\title{
Leukotriene receptor antagonist addition to intranasal steroid: systematic review and meta-analysis*
}

\author{
Kachorn Seresirikachorn 1,2, Joaquim Mullol ${ }^{3}$, Kanda Limitlaohaphan4, \\ Vararuthai Asvapoositkul', Kornkiat Snidvongs, \\ ' Department of Otolaryngology, Faculty of Medicine, Chulalongkorn University, Bangkok, Thailand \\ 2 Endoscopic Nasal and Sinus Surgery Excellence Center, King Chulalongkorn Memorial Hospital, Bangkok, Thailand \\ 3 Rhinology Unit \& Smell Clinic, ENT Department, Hospital Clinic, IDIBAPS, Universitat de Barcelona, CIBERES, Barcelona, Catalonia, \\ Spain \\ ${ }^{4}$ Relief and Community Health Bureau, The Thai Red cross Societies, Bangkok, Thailand \\ ${ }^{5}$ Bangkok Metropolitan Administration General Hospital. Bangkok, Thailand
}

Rhinology 59: 1, 2- 9, 2021

https://doi.org/10.4193/Rhin20.126

*Received for publication:

April 2, 2020

Accepted: June 15, 2020

\begin{abstract}
Background: Intranasal corticosteroids (INCS) and leukotriene receptor antagonist (LTRA) have different mechanisms of action. The combination of INCS and LTRA (INCS+LTRA) are utilized to control the allergic rhinitis (AR) symptoms. The effects of this combination have not been made evident yet.
\end{abstract}

Methodology: Randomized controlled trials studying the effects of INCS+LTRA vs INCS in monotherapy on rhinoconjunctivitis symptoms in patients with AR were included. Data were pooled for meta-analysis. The outcomes were nasal symptoms, ocular symptoms, disease-specific quality of life (QOL), and adverse events.

Results: Six studies (358 participants) met the inclusion criteria. There were no differences between INCS+LTRA and INCS monotherapy on composite nasal symptom score, total daytime symptom score, total night time symptom score, disease-specific QOL and adverse events. The results favoured the effects of INCS-LTRA on ocular symptoms.

Conclusions: The effects of the INCS+LTRA combination are not different from INCS in monotherapy in the improvement of both nasal symptoms and patient's QOL. The combination may, however, be better on improving ocular symptoms.

Key words: corticosteroids, leukotriene receptor antagonist, allergic rhinitis, asthma

\section{Introduction}

With multiple anti-inflammatory activities, intranasal corticosteroid (INCS) is an effective medicine for treating allergic rhinitis (AR). INCS may be prescribed to AR patients with moderate to severe or persistent symptoms having nasal obstruction as major symptom ${ }^{(1,2)}$. INCS binds to a specific cytoplasmic glucocorticoid receptor then activates anti-inflammatory gene transcription and represses pro-inflammatory gene transcription ${ }^{(3)}$. As a result, the lymphocyte activation and cytokine production are inhibited, which decrease the migration of inflammatory cells to the nasal mucosa ${ }^{(4,5)}$. The anti-inflammatory effects of INCS effectively control the allergic response and relieve the clinical symptoms, including itching, sneezing, rhinorrhea, nasal obstruction, and ocular symptoms.
Leukotriene is a pro-inflammatory mediator which plays a key role in the pathogenesis of AR. In addition to eosinophil chemotaxis, leukotriene release causes vasodilation, increased vascular permeability, smooth muscle constriction and mucus hypersecretion in the airways ${ }^{(6-8)}$. Therefore, the effects of leukotriene on the nasal vasculature, such as vascular permeability and vasodilation play a role in producing symptoms of the mucosal swelling ${ }^{(9)}$. The related clinical symptoms include nasal obstruction, hypersecretion, bronchoconstriction, and bronchial hyperresponsiveness ${ }^{(7)}$. Clinical studies found that topical leukotriene D4 increased blood flow and nasal airway resistance without causing sneezing, rhinorrhea, and nasal itching ${ }^{(10,11)}$. Leukotriene receptor antagonist (LTRA) binds to cysteinyl leukotriene 1 (CysLT1) receptor and reduces eosinophilic 
inflammation in upper-airway inflammatory diseases such as rhinitis and nasal polyposis ${ }^{(8,12)}$ and eosinophil chemotaxis ${ }^{(13)}$. CysLTs-induced productions of IL-5 and IL-13 from group 2 innate lymphoid cells (ILC2s) were completely inhibited by CysLT1 antagonist ${ }^{(14)}$. As a result, LTRA reduces nasal inflammation, especially nasal congestion ${ }^{(9)}$. While LTRA decreased T-helper 1 (Th1) cells and increased T-regulatory (Treg) cells in peripheral blood, INCS decreased Th1 cells and Th2 and increased Treg cells in nasal mucosa ${ }^{(15)}$. In addition, eosinophil cationic protein (ECP), histamine, and cysteinyl-leukotrienes (CysLTs) were significantly decreased greater by INCS and INCS+LTRA treatments than LTRA monotherapy. This trend was reflected with combination therapy ${ }^{(15)}$.

Although INCS and LTRA have different mechanisms of action, the combination of an LTRA with an INCS may provide additional effects on the improvement of nasal symptoms of AR. Combination therapy is an option which may be offered to patients with $A R$ who do not respond to monotherapy ${ }^{(1,2)}$. Potentially, this combination of INCS and LTRA (INCS+LTRA) may also be more effective in controlling the symptoms of AR patients with/without asthma. This systematic review aimed to assess the effects of INCS+LTRA vs INCS in monotherapy in relieving rhinoconjunctivitis symptoms of AR.

\section{Materials and methods}

Eligibility criteria

This systematic review followed The Preferred Reporting Items for Systematic Reviews and Meta-Analyses (PRISMA)16. Randomized controlled trials (RCTs) studying the effects of INCS+LTRA versus INCS in monotherapy in patients with AR were included. The diagnostic criteria of AR followed the Allergic Rhinitis and its Impact on Asthma (ARIA) guidelines ${ }^{(1)}$. RCTs studying INCSs and LTRAs, at any dose, frequency, and duration were included in the analysis. The selected outcomes were nasal symptoms, ocular symptoms, disease-specific QOL, and adverse events. RCTs published in a language other than English were excluded. RCTs with mixed populations of AR and non-AR were excluded unless the outcomes for patients with AR could be isolated.

\section{Information sources and search strategy}

Electronic systematic searches for RCTs were conducted with no publication year, or publication status restrictions. The last search was performed on 19 May 2020. Literature searches were performed using Ovid MEDLINE, Ovid EMBASE, CENTRAL, and Web of Science. References of the included studies were searched for identifying any missing published or unpublished trials. The searched term used was (Leukotriene receptor antagonist OR Leukotriene receptor blocking agent OR antileukotriene OR Montek OR Montelukast OR Singulair) AND (Triamcinolone Acetonide OR Nasacort OR Nasonex OR Mometasone Furoate OR Rhinocort OR Budesonide OR Pulmicort OR Flonase OR

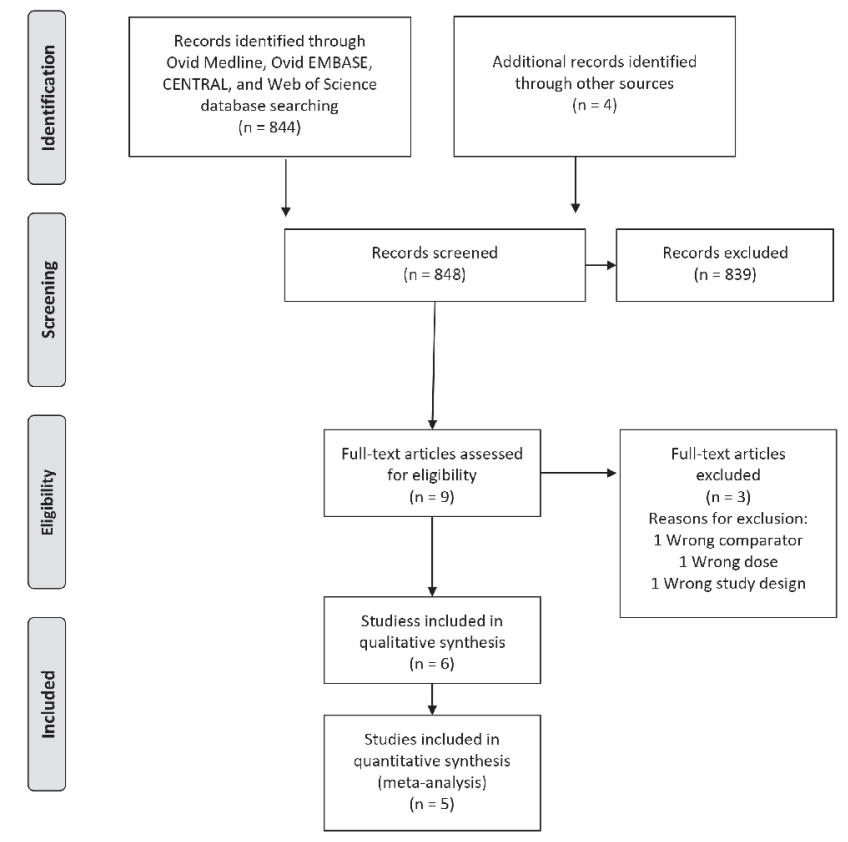

Figure 1. Flow diagram of study selection for the systematic review and meta-analysis.

Fluticasone OR Dexamathasone OR Betamethasone OR Omnaris OR Ciclesonide OR Veramyst OR Flunisolide OR Nasalide OR Beclomathasone OR hydrocortisone) AND (allergic rhinitis).

\section{Study selection and data collection}

Two review authors ( $K L$ and $V A$ ) independently performed trial selection by title and abstract screening based on predetermined eligibility criteria. The full-text articles of the selected RCTs were reviewed. Two authors (KSe and KL) extracted details of the included studies. When insufficient information or conflicting data were found during the data collection, the corresponding author was approached for further information. Any disagreements over data were resolved by the fifth author (KSn) if necessary. The collected data included: study type, number of participants, mean age, gender, primary outcomes and secondary outcomes. The primary outcomes were nasal symptoms, ocular symptoms, and disease-specific QOL. The secondary outcomes were adverse events. Data of patients with comorbid asthma were extracted separately when possible, for subgroup analysis.

\section{Risk of bias in included studies}

The quality of included RCTs was assessed by evaluating the risks of bias as guided by the Cochrane Handbook for Systematic Reviews of Interventions ${ }^{(17)}$. Five domains were assessed: random sequence generation, allocation concealment, blinding of outcome assessment, incomplete outcome data, and selective reporting. The included studies had a low risk of bias when the methods used for each domain were clearly described. When 
Table 1. Characteristics of included studies.

\begin{tabular}{|c|c|c|c|c|c|c|c|c|c|c|}
\hline First author & Year & $\begin{array}{l}\text { Study } \\
\text { Type }\end{array}$ & Disease phenotype & $\begin{array}{l}\text { Patients } \\
\text { Age } \\
\text { (years } \\
\text { old) }\end{array}$ & $\begin{array}{l}\text { Number } \\
\text { of pa- } \\
\text { tients }\end{array}$ & LTRA drug & $\begin{array}{l}\text { LTRA } \\
\text { dose } \\
\text { (mg/d) }\end{array}$ & INCS drug & $\begin{array}{l}\text { INCS } \\
\text { dose } \\
(\mu \mathrm{g} / \mathrm{d})\end{array}$ & $\begin{array}{c}\text { Duration } \\
\text { of treat- } \\
\text { ment } \\
\text { (weeks) }\end{array}$ \\
\hline Di lorenzo ${ }^{(19)}$ & 2004 & $\begin{array}{l}\mathrm{RPCT}, \\
\mathrm{DB}\end{array}$ & $\begin{array}{c}\text { Moderate to severe } \\
\text { SAR }\end{array}$ & $12-50$ & 100 & Montelukast & 10 & $\begin{array}{l}\text { Fluticasone } \\
\text { propionate }\end{array}$ & 200 & 6 \\
\hline Modgill (20) & 2010 & RCT & $\mathrm{AR}$ & $15-55$ & 90 & Montelukast & 10 & $\begin{array}{l}\text { Fluticasone } \\
\text { propionate }\end{array}$ & 400 & 4 \\
\hline Esteitie ${ }^{(21)}$ & 2010 & $\begin{array}{l}\text { RPCT, } \\
\text { DB }\end{array}$ & PAR & $18-55$ & 54 & Montelukast & 10 & $\begin{array}{l}\text { Fluticasone } \\
\text { propionate }\end{array}$ & 200 & 2 \\
\hline Tatar ${ }^{(22)}$ & 2013 & RCT & $\begin{array}{l}\text { Moderate to severe } \\
\text { persistent } A R\end{array}$ & $17-67$ & 56 & Montelukast & 10 & $\begin{array}{l}\text { Mometasone } \\
\text { furoate }\end{array}$ & 200 & 4 \\
\hline Goh $^{(23)}$ & 2014 & $\begin{array}{l}\text { RPCT, } \\
\text { DB }\end{array}$ & $\begin{array}{c}\text { Moderate to severe } \\
\text { SAR }\end{array}$ & $>12$ & 128 & Montelukast & 10 & $\begin{array}{l}\text { Fluticasone } \\
\text { propionate }\end{array}$ & 200 & 8 \\
\hline Chen ${ }^{(24)}$ & 2019 & RCT & $\begin{array}{c}\text { Moderate to severe } \\
\text { SAR }\end{array}$ & $18-60$ & 41 & Montelukast & 10 & Budesonide & 256 & 2 \\
\hline
\end{tabular}

LTRA, leukotriene receptor antagonist; INCS, intranasal corticosteroid; mg/d, milligram per day; $\mu \mathrm{g} / \mathrm{d}$, microgram per day; RPCT, Randomized placebocontrolled trial; RCT, Randomized controlled trial; DB, Double-blind; SAR, seasonal allergic rhinitis; PAR, perennial rhinitis.

the described methods for each domain showed a high risk of bias, that study was classified as high risk. When there was not enough information to determine the risk, the RCT was defined as unclear risk of bias.

\section{Data synthesis and statistical analysis}

Data were pooled for meta-analysis. Odds ratios (OR) and 95\% confidence intervals $(\mathrm{Cl})$ were used for dichotomous data. Standardized Mean Differences (SMD) and 95\% Cls were used for continuous data. The heterogeneity or the discrepancy in the estimates of treatment effects from different trials was assessed by the $\mathrm{I}^{2}$ statistic. An $\mathrm{I}^{2}$ of less than $40 \%, 40-60 \%$, or $>60 \%$ represented low, moderate, and substantial heterogeneity, respectively. A fixed-effect method was used when statistical heterogeneity was low. When the statistical heterogeneity was high, a random-effect method was used for a more conservative estimate of the difference. Statistical assessments were performed using Review Manager (RevMan) version 5.3 ${ }^{(18)}$ (The Nordic Cochrane Centre, The Cochrane Collaboration, Copenhagen, Denmark).

\section{Results}

\section{Study selection}

There were 848 studies identified and retrieved, 844 studies were from electronic searches, and 4 studies were from manual searches. During the title and abstract screening, 839 studies were excluded due to irrelevant references. Three studies were excluded after full-text screening (Figure 1). Six studies were finally included ${ }^{(19-24)}$ in the qualitative synthesis. A randomized controlled trial by Tatar et al. ${ }^{(22)}$ did not compare between the groups and did not report the standard deviation. Therefore, the data from this study could not be pooled for meta-analysis. Finally, a total of 5 studies were included for the meta-analy$\mathrm{sis}^{(19-21,23,24)}$. Characteristics of the included studies are shown in Table 1. A flow chart of the study retrieval and selection is presented in Figure 1.

\section{Participants}

In these 6 studies, there were a total of 358 participants. The mean age was 28.9 years, being $41.6 \%$ male. The diagnosis of AR was confirmed by skin tests or serum-specific lgE in 298 patients. Three RCTs studied paediatric and adult patients ${ }^{(19,20,23)}$ while three RCTs studied only adult patients ${ }^{(21,22,24)}$. Two RCTs studied patients with seasonal AR (SAR) ${ }^{(19,24)}$, while two studied perennial AR (PAR), one with persistent disease ${ }^{(21,22)}$. Concerning severity, four RCTs studied moderate to severe $A R^{(19,22-24)}$. One trial included AR patients with comorbid mild asthma, but the data were not reported separately ${ }^{(21)}$. Patients with asthma were excluded from five trials $\mathrm{s}^{(19,20,22-24)}$.

\section{Intervention}

One RCT used mometasone furoate $200 \mu \mathrm{g}$ per day ${ }^{(22)}$, three used fluticasone propionate $200 \mu \mathrm{g}$ per day $(50 \mu \mathrm{g}$ /actuation, two actuations into each nostril once a day) ${ }^{(19,21,23)}$, one used fluticasone propionate $400 \mu \mathrm{g}$ per day ( $200 \mu \mathrm{g}$ into each nostril once a day) (20), and one used budesonide $256 \mu \mathrm{g}$ per day (64 $\mu \mathrm{g}$ into each nostril twice daily) ${ }^{(24)}$. All RCTs used oral montelukast (10mg/day) as the LTRA ${ }^{(19-24)}$. Treatment duration ranged from 2 to 8 weeks. None of the RCTs conducted a long-term study.

\section{Outcomes}

Nasal symptom score. The nasal symptom was scored using 


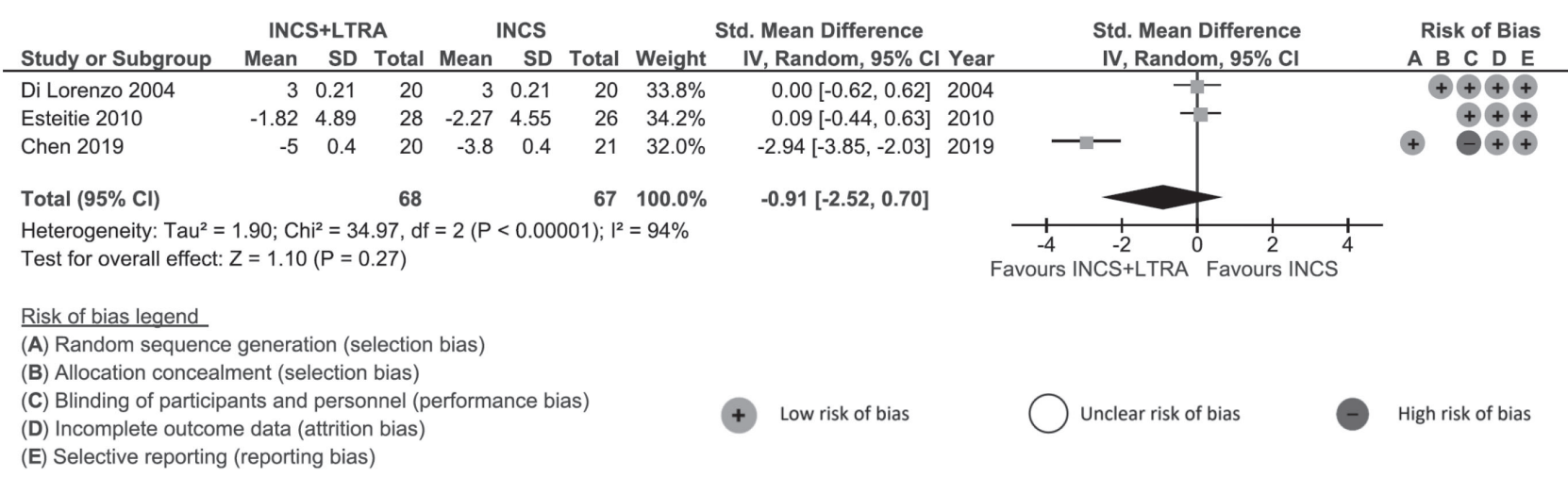

Figure 2. Improvement in the composite nasal symptom score: Intranasal corticosteroid plus leukotriene receptor antagonist vs intranasal corticosteroid in monotherapy. Abbreviations: SMD, standardized mean difference; IV, inverse variance; Random, Random effects; Cl, confidence interval; df: degrees of freedom; INCS, intranasal corticosteroid: LTRA, leukotriene receptor antagonist.

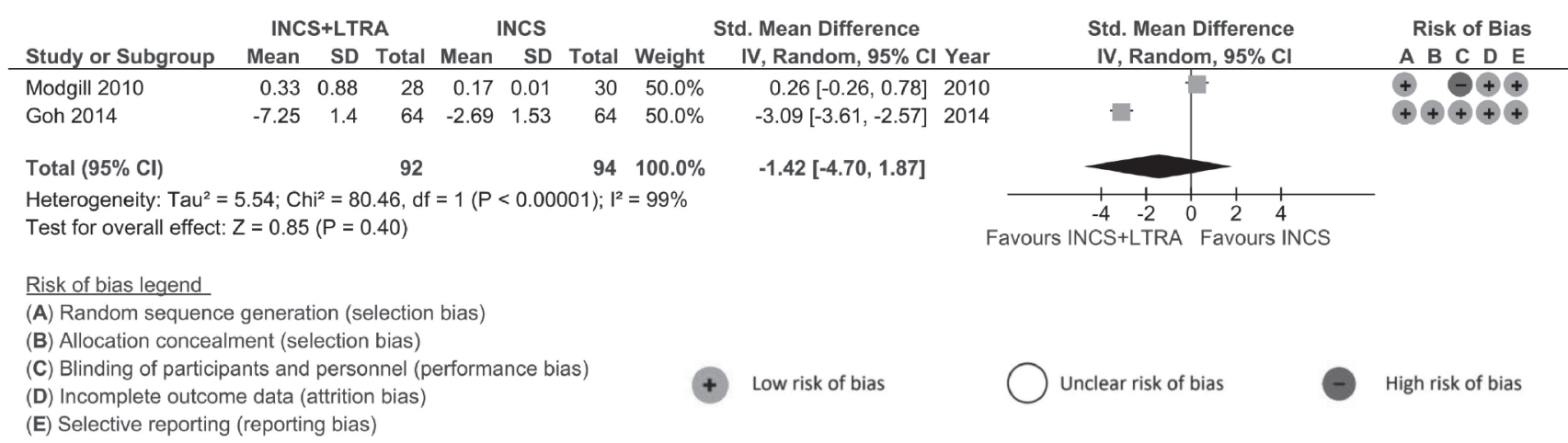

Figure 3. Improvement in the total daytime symptom score: Intranasal corticosteroid plus leukotriene receptor antagonist vs Intranasal corticosteroid. Abbreviations: SMD, standardized mean difference, IV: inverse variance, Random: Random effects, Cl: confidence interval, df: degrees of freedom, INCS: Intranasal corticosteroid, LTRA: leukotriene receptor antagonist.

a 4-point scale (0 none, 1 mild, 2 moderate, and 3 severe) (19,21-23). One study used a $10 \mathrm{~cm}$ visual analog scale $(0 \mathrm{~cm}=$ no symptoms and $10 \mathrm{~cm}=$ most severe and bothersome symptom) ${ }^{(24)}$. The scoring system was not described in one study ${ }^{(20)}$. Four RCTs assessed composite nasal symptom score $\mathrm{e}^{(19,20,22,24)}$. There was no significant statistical difference in the composite nasal symptom score between the INCS+LTRA and INCS in monotherapy (SMD $-0.91,95 \% \mathrm{Cl}-2.52$ to $0.70, \mathrm{p}=0.27,3 \mathrm{RCTs}){ }^{(19,22,24) \text {. }}$ An $1^{2}$ of $94 \%$ represented substantial heterogeneity of the 3 RCTs ${ }^{(19,21,24)}$. There were no significant differences between the INCS+LTRA and INCS in monotherapy in total daytime symptom score (SMD - $1.42,95 \% \mathrm{Cl}-4.70$ to $1.87, \mathrm{p}=0.40,2 \mathrm{RCTs})^{(20,23)}$ and total nighttime symptom score (SMD $-0.55,95 \% \mathrm{Cl}-3.46$ to 2.35 , $\mathrm{p}=0.71,2 \mathrm{RCTs})^{(20,23)}$. An $\mathrm{I}^{2}$ of $99 \%$ represents substantial heterogeneity of the $2 \mathrm{RCTs}{ }^{(20,23)}$. The data are displayed in Figures 2-4. The individual nasal symptom score was assessed in five RCTs ${ }^{(19-}$ 22, 24). One RCT did not report the standard deviation for each individual nasal symptom score and could not be imputed ${ }^{(22)}$. There were no significant differences between INCS+LTRA and INCS in monotherapy in nasal congestion (SMD -0.98; 95\%Cl -2.37 to $0.42, p=0.17,4 \mathrm{RCTs})^{(19-21,24)}$, rhinorrhea (SMD -0.73;
$95 \% \mathrm{Cl}-2.26$ to $0.81, \mathrm{p}=0.35,4 \mathrm{RCTs})^{(19-21,24)}$, itching (SMD -0.73; $95 \% \mathrm{Cl}-2.99$ to $1.53, \mathrm{p}=0.53,3 \mathrm{RCTs})^{(19,20,24)}$ and sneezing (SMD $-0.19 ; 95 \% \mathrm{Cl}-1.76$ to $1.38, \mathrm{p}=0.81,4 \mathrm{RCTs})^{(19-21,24)}$. The heterogeneity was substantial for nasal congestion, rhinorrhea, nasal itching, and sneezing $\left(I^{2}\right.$ of $93 \%, 94 \%, 97 \%$, and $96 \%$, respectively). Reduction of nasal symptoms in the subgroup of patients with comorbid asthma could not be assessed as patients with asthma were excluded from most studies.

Ocular symptom score. The assessed ocular symptoms were tearing, ocular itching, redness, and puffiness. The ocular symptom was scored by a 4-point scale ( 0 none, 1 mild, 2 moderate, and 3 severe. One RCT assessed total ocular symptom score $^{(23)}$. The results favoured the effects of INCS+LTRA over the INCS in monotherapy. The difference was statistically significant (SMD -2.87, $95 \% \mathrm{Cl}-3.75$ to $-1.99, \mathrm{p}<0.00001,1 \mathrm{RCT})^{(23)}$.

Disease-specific QOL. Three RCTs assessed disease-specific QOL score ${ }^{(21-23)}$. The Rhinoconjunctivitis Quality of Life Questionnaire (RQLQ) ${ }^{(25)}$ was used in two RCTs only ${ }^{(21,23)}$. The RQLQ questionnaire comprises 25 questions distributed in 6 domains (activity 


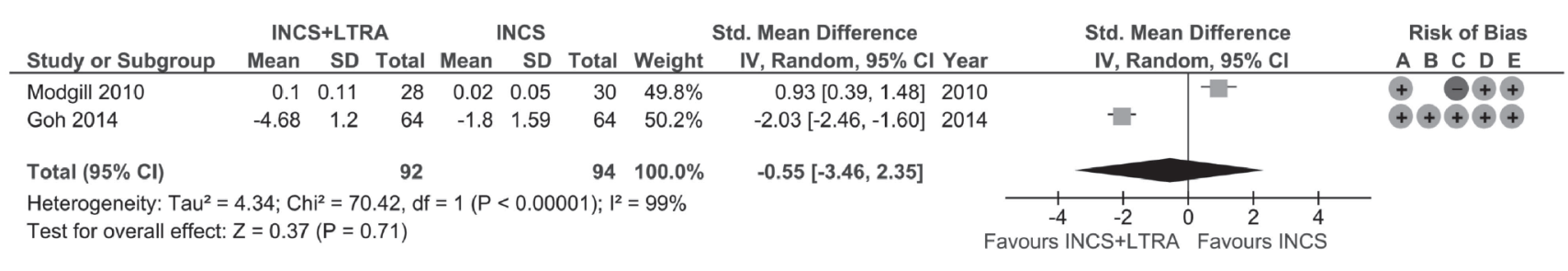

Risk of bias legend

(A) Random sequence generation (selection bias)

(B) Allocation concealment (selection bias)

(C) Blinding of participants and personnel (performance bias)

(D) Incomplete outcome data (attrition bias)

Low risk of bias

Unclear risk of bias

High risk of bias

Figure 4. Improvement in the total nighttime symptom score: intranasal corticosteroid plus leukotriene receptor antagonist vs intranasal corticosteroid. Abbreviations: SMD, standardized mean difference; IV, inverse variance; Random, Random effects; $\mathrm{Cl}$, confidence interval; df, degrees of freedom; INCS, intranasal corticosteroid; LTRA, leukotriene receptor antagonist.

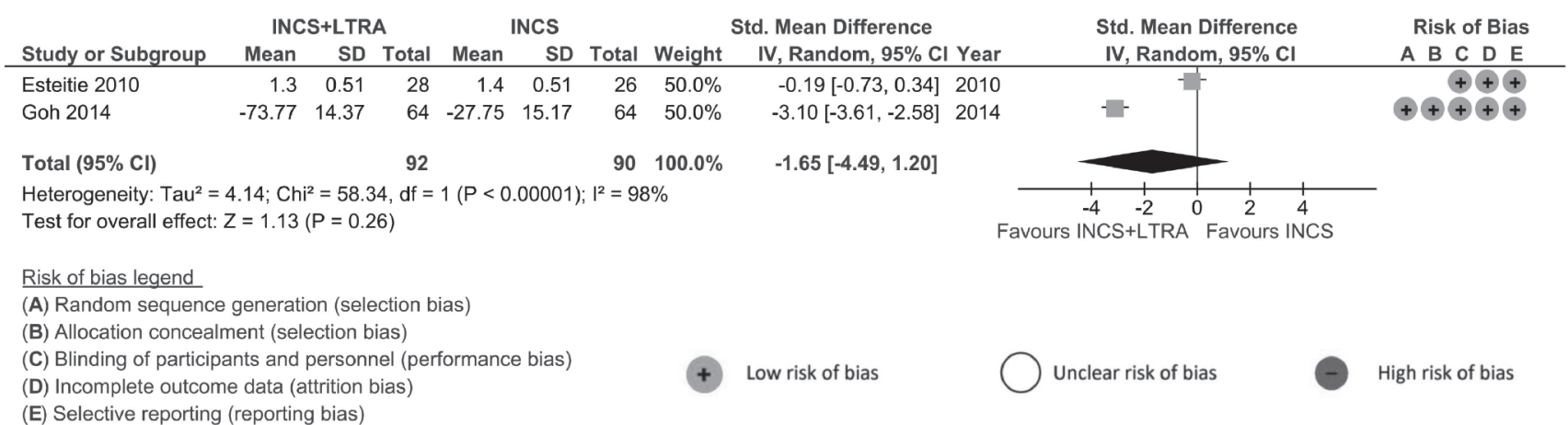

Figure 5. Improvement in the disease-specific quality of life score: Intranasal corticosteroid plus leukotriene receptor antagonist vs Intranasal corticosteroid. Abbreviations: SMD, standardized mean difference; IV, inverse variance; Random, Random effects; Cl, confidence interval; df, degrees of freedom; INCS, Intranasal corticosteroid; LTRA, leukotriene receptor antagonist.

limitations, practical problems, nose symptoms, eye symptoms, non-hay fever symptoms, and emotional problems). Each item was rated on a 7-point scale from 0 (no impairment) to 6 (severely impaired). A high score corresponds to the low quality of life. The miniRQLQ comprised 14 questions distributed in five domains (activity limitations, practical problems, nasal symptoms, eye symptoms, and other symptoms) and was used in one trial ${ }^{(22)}$. This trial did not report; however, the standard deviation for the disease-specific QOL score and could not be imputed $^{(22)}$. There was no significant difference between the INCS+LTRA and INCS in monotherapy (SMD -1.65; 95\%CI -4.49 to $1.20, p=0.26,2 \mathrm{RCTs})^{(21,23)}$. The data are displayed in Figure 5.

\section{Adverse events}

The number of patients with adverse events was reported by four RCTs $s^{(19,21,22,24)}$. There was no significant difference in adverse events between the INCS+LTRA and INCS in monotherapy (Risk Ratio $1.50,95 \% \mathrm{Cl} 0.54$ to $4.18, \mathrm{p}=0.44$ ).

Risk of bias in the included studies

From the included studies, $50 \%$ and $40 \%$ had a low risk of bias in random sequence generation and allocation concealment respectively, while $50 \%$ had a high risk of bias in the blinding of outcome assessment. All studies (100\%) had a low risk of bias in incomplete outcome data, while $83 \%$ had a low risk of bias in selective reporting. Overall, the included studies had selection bias and performance bias, whereas they had low risks in attrition bias and reporting bias (Figure 6).

\section{Discussion}

The use of LTRA+INCS combination for treating AR has been a controversial issue in recent years. The results of this study failed to demonstrate the benefits of INCS+LTRA compared to INCS in monotherapy on the improvement in nasal symptoms and disease-specific QOL. In line with our findings, when the olfactory function was assessed by Dalgic et al., LTRA did not add benefits to INCS ${ }^{(26)}$. However, the combination had beneficial effects on extra nasal symptoms. Based on one RCT, the INCS+LTRA combination significantly decreased ocular symptoms compared to the INCS in monotherapy. Goh et al. ${ }^{(23)}$ randomized 128 patients with AR to receive fluticasone propionate nasal spray together with either montelukast tablets or 


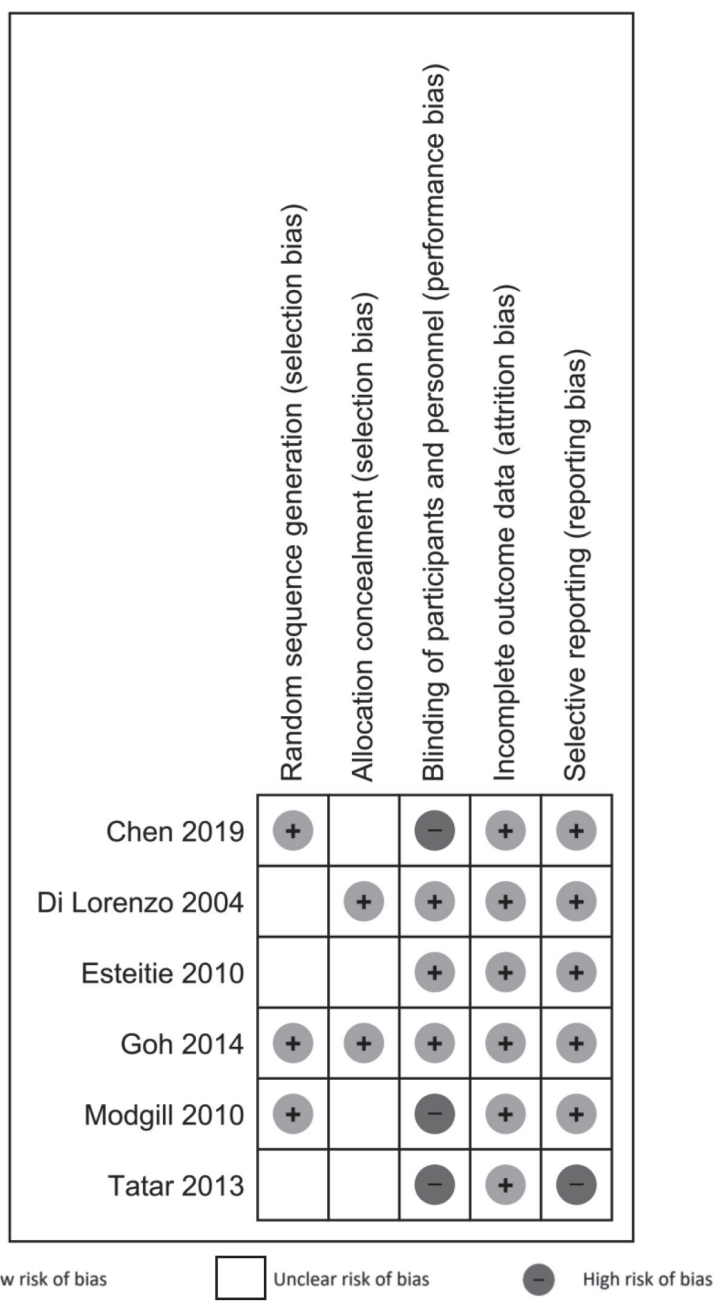

Figure 6. Risk of bias summary: each risk of bias item for each included study.

placebo. The combination demonstrated greater effects in both ocular symptom scores and the eye domain of the RQLQ questionnaires. Likewise, previous articles reported that the combination controlled asthmatic symptoms better than the INCS in monotherapy ${ }^{(27-30)}$. The INCS+LTRA combination improved lower airway symptoms by the effects on bronchial smooth muscle contraction, vasodilatation, and mucus hypersecretion6.

In contrast to the results of the present study, a previous metaanalysis by Feng et al. ${ }^{(31)}$ favoured the INCS+LTRA effects vs INCS in monotherapy on nasal symptoms improvement, including total nasal symptom, rhinorrhea, and sneezing scores. That meta-analysis was published in Chinese, had different inclusion criteria, included some non-randomized trials ${ }^{(31)}$ and even did not include one important $\mathrm{RCT}^{(22)}$.

Seidman et al. ${ }^{(2)}$, in a clinical practice guideline, does not recommend the use of INCS+LTRA combination after the failure of INCS in monotherapy for the management AR and it is not recommended either by the International Consensus Statement on Allergy and Rhinology: Allergic Rhinitis (ICAR:AR) regarding its effectiveness ${ }^{(32)}$. In practice, INCS in monotherapy or the formulation MP-AzeFlu of INCS should be an initial treatment for patients with moderate to severe persistent AR or nasal obstruction ${ }^{(32,33)}$. The findings of our meta-analysis do not recommend the use of INCS+LTRA combination in AR patients who fail after INCS in monotherapy. The INCS+LTRA combination may, however, be considered to improve persistent extra nasal symptoms, including ocular symptoms. The clinical guidelines recommend against LTRA monotherapy for the management of AR because LTRA was more expensive and equally as effective as or less effective than oral antihistamines for $\mathrm{AR}^{\left({ }^{(34)} \text {; moreover }\right.}$ it is less effective than INCS2. LTRA combined with oral $\mathrm{H} 1$ antihistamine might be considered when failure of antihistamine monotherapy ${ }^{(2,32,35)}$. In this situation, the formulation MP-AzeFlu of INCS is better evidence-based option validated by previous studies $^{(36)}$, meta-analysis ${ }^{(37,38)}$, and clinical guidelines ${ }^{(3,39)}$. Besides, a double-dosing of INCS is another option to be considered, this being favoured by a meta-analysis in adult patients ${ }^{(40)}$. Other drug combinations such as nasal decongestants with INCS have not proved any beneficial effect in a meta-analysis ${ }^{(40)}$. The limitation of our study was the quality and heterogeneity of the included studies. Most studies had risks of bias in several ways. The common biases were allocation concealment and blinding. Two RCTs included in the meta-analysis had a high risk of bias in blinding of participants and personnel ${ }^{(20,24)}$. The Substantial heterogeneity was found for the outcomes of total daytime and nighttime symptoms scores. Thus, the overall effect may be invalid. There was homogeneity among the three randomized controlled trials reporting no difference between the effects of INCS+LTRA vs INCS in monotherapy ${ }^{(19-21)}$. It is worth noting that these three RCTs had significant risks of bias and the study, which favored the use of INCS+LTRA had moderate to high quality ${ }^{(23,24)}$. Although the reduction of ocular symptoms was shown, these findings were based on only one trial, being this beneficial effect quite inconclusive. This analysis did not assess the effects in patients with asthma because they were excluded from five trials ${ }^{(19,20,22-24)}$. Well-conducted randomized controlled trials are required for further evidence-based recommendations.

\section{Conclusion}

Evidence from five randomized controlled trials in patients with AR did not show benefit of the INCS+LTRA combination when compared to INCS in monotherapy. Nasal symptoms and disease-specific QOL were not different between the two treatments. Although observed, the reduction of ocular symptoms by INCS + LTRA was inconclusive because it was based on a single trial. However, the INCS+LTRA combination was safe and well-tolerated. When INCS fails to improve allergic rhinitis, the INCS+ azelastine combination should be a better option. 
When oral $\mathrm{H} 1$ antihistamine fails, oral $\mathrm{H} 1$ antihistamine +LTRA combination might be considered. LTRA should not be used as monotherapy for the treatment of AR.

\section{Acknowledgements}

The authors would like to thank Likhit Khattiyawittayakun for his technical advice. This is an unfunded project.

\section{Authorship contribution}

KSe: study design, search, study selection, data collection, data analysis, drafting the article, and final approval. JM: expert opinion, revising the article, and final approval. KL: search, study selection, data collection, revising the article, and final approval
VA: search, study selection, and final approval. KSn: conception, study design, data analysis, drafting the article, and final approval

\section{Conflict of interest}

JM has been a member of the advisory board or speaker bureau or received research grants from Allakos, ALK, AstraZeneca, Genentech, GlaxoSmithKline, Menarini, Mitsubishi-Tanabe, MSD, Mylan-MEDA Pharma, Novartis, Sanofi-Genzyme \& Regeneron, UCB, Uriach Group. KSN received Honoraria for speaking at symposia from Merck Sharp \& Dohme and Menarini. KSE, KL and VA declare that they have no conflict of interest.

\section{References}

1. Bousquet J, Khaltaev N, Cruz AA, Denburg J, Fokkens WJ, Togias A, et al. Allergic Rhinitis and its Impact on Asthma (ARIA) 2008 update (in collaboration with the World Health Organization, GA2LEN and AllerGen). Allergy. 2008;63(SUPPL. 86):8-160.

2. Seidman MD, Gurgel RK, Lin SY, Schwartz SR, Baroody FM, Bonner JR, et al. Clinical practice guideline: Allergic rhinitis executive summary. Otolaryngol Head Neck Surg. 2015;152(2):197-206.

3. Snidvongs K, Thanaviratananich S. Update on Intranasal Medications in Rhinosinusitis. Curr Allergy Asthma Rep. 2017;17(7):47.

4. Lee SH. Mechanisms of Glucocorticoid Action in Chronic Rhinosinusitis. Allergy Asthma Immunol Res. 2015;7(6):534-7.

5. Mullol J, Obando A, Pujols L, Alobid I. Corticosteroid treatment in chronic rhinosinusitis: the possibilities and the limits. Immunol Allergy Clin North Am 2009;29(4):657-68.

6. Nathan RA. Pharmacotherapy for allergic rhinitis: a critical review of leukotriene receptor antagonists compared with other treatments. Ann Allergy Asthma Immunol. 2003;90(2):182-90; quiz 90-1, 232.

7. Lipworth BJ. Leukotriene-receptor antagonists. Lancet. 1999;353(9146):57-62.

8. De Corso E, Anzivino R, Galli J, Baroni S, Di Nardo W, De Vita C, et al. Antileukotrienes improve naso-ocular symptoms and biomarkers in patients with NARES and asthma. Laryngoscope. 2019;129(3):551-7.

9. Maynard ML, Ernst ME. Leukotriene receptor antagonists in the treatment of allergic rhinitis. Ann Pharmacother. 2001;35(10):12747.

10. Bisgaard H, Olsson P, Bende M. Effect of leukotriene D4 on nasal mucosal blood flow, nasal airway resistance and nasal secretion in humans. Clin Allergy. 1986;16(4):289-97.

11. Okuda M, Watase T, Mezawa A, Liu CM. The role of leukotriene D4 in allergic rhinitis. Ann Allergy. 1988;60(6):537-40.

12. Mullol J, Callejas FB, Méndez-Arancibia E, Fuentes M, Alobid I, Martínez-Antón A, et al.
Montelukast reduces eosinophilic inflammation by inhibiting both epithelial cell cytokine secretion (GM-CSF, IL-6, IL-8) and eosinophil survival. J Biol Regul Homeost Agents. 2010;24(4):403-11

13. Munoz NM, Douglas I, Mayer D, Herrnreiter A, Zhu X, Leff AR. Eosinophil chemotaxis inhibited by 5 -lipoxygenase blockade and leukotriene receptor antagonism. Am J Respir Crit Care Med. 1997;155(4):1398-403.

14. Tojima I, Matsumoto K, Kikuoka H, Hara S, Yamamoto S, Shimizu S, et al. Evidence for the induction of Th2 inflammation by group 2 innate lymphoid cells in response to prostaglandin D2 and cysteinyl leukotrienes in allergic rhinitis. Allergy. 2019;74(12):2417-26.

15. Chen H, Lou H, Wang Y, Cao F, Zhang L, Wang C. Comparison of the efficacy and mechanisms of intranasal budesonide, montelukast, and their combination in treatment of patients with seasonal allergic rhinitis. Int Forum Allergy Rhinol. 2018;8(11):1242-52.

16. Moher D, Liberati A, Tetzlaff J, Altman DG. Preferred reporting items for systematic reviews and meta-analyses: the PRISMA statement. PLoS Med. 2009;6(7):e1000097.

17. Higgins JP, Altman DG, Gotzsche PC, Juni P, Moher D, Oxman AD, et al. The Cochrane Collaboration's tool for assessing risk of bias in randomised trials. BMJ. 2011;343:d5928.

18. Review Manager (RevMan) 5.1.6 ed. Copenhagen: The Nordic Cochrane Centre. The Cochrane Collaboration; 2011.

19. Di Lorenzo G, Pacor ML, Pellitteri ME, Morici G, Di Gregoli A, Lo Bianco C, et al. Randomized placebo-controlled trial comparing fluticasone aqueous nasal spray in mono-therapy, fluticasone plus cetirizine, fluticasone plus montelukast and cetirizine plus montelukast for seasonal allergic rhinitis. Clin Exp Allergy. 2004;34(2):259-67.

20. Modgill V, Badyal DK, Verghese A. Efficacy and safety of montelukast add-on therapy in allergic rhinitis. Methods Find Exp Clin Pharmacol. 2010;32(9):669-74.

21. Esteitie $R$, deTineo M, Naclerio RM, Baroody
FM. Effect of the addition of montelukast to fluticasone propionate for the treatment of perennial allergic rhinitis. Ann Allergy Asthma Immunol. 2010;105(2):155-61.

22. Tatar EC, Surenoglu UA, Ozdek A, Saylam G, Korkmaz $\mathrm{H}$. The effect of combined medical treatment on quality of life in persistent allergic rhinitis. Indian J Otolaryngol Head Neck Surg. 2013;65(Suppl 2):333-7.

23. Goh BS, Ismail MI, Husain S. Quality of life assessment in patients with moderate to severe allergic rhinitis treated with montelukast and/or intranasal steroids: a randomised, double-blind, placebo-controlled study. J Laryngol Otol. 2014;128(3):242-8.

24. Chen H, Zhang L, Lou H, Wang Y, Cao F, Wang C. A Randomized Trial of Comparing a Combination of Montelukast and Budesonide With Budesonide in Allergic Rhinitis. Laryngoscope. 2019.

25. Juniper EF, Thompson AK, Ferrie PJ, Roberts JN. Development and validation of the mini Rhinoconjunctivitis Quality of Life Questionnaire. Clin Exp Allergy. 2000;30(1):132-40.

26. Dalgic A, Dinc ME, Ulusoy S, Dizdar D, Is A, Topak M. Comparison of the effects of nasal steroids and montelukast on olfactory functions in patients with allergic rhinitis. Eur Ann Otorhinolaryngol Head Neck Dis. 2017;134(4):213-6.

27. Virchow JC, Mehta A, Ljungblad L, Mitfessel H. A subgroup analysis of the MONICA study: a 12-month, open-label study of add-on montelukast treatment in asthma patients. J Asthma. 2010;47(9):986-93.

28. Korn D, Van den Brande P, Potvin E, Dramaix M, Herbots E, Peche R. Efficacy of add-on montelukast in patients with non-controlled asthma: a Belgian open-label study. Curr Med Res Opin. 2009;25(2):489-97.

29. Keith PK, Koch C, Djandji M, Bouchard J, Psaradellis E, Sampalis JS, et al. Montelukast as add-on therapy with inhaled corticosteroids alone or inhaled corticosteroids and long-acting beta-2-agonists in the management of patients diagnosed with asthma and concurrent allergic rhinitis (the RADAR 
trial). Can Respir J. 2009;16 Suppl A:17a-31a.

30. Price DB, Swern A, Tozzi CA, Philip G, Polos P. Effect of montelukast on lung function in asthma patients with allergic rhinitis: analysis from the COMPACT trial. Allergy. 2006;61(6):737-42.

31. Feng $S$, Fan $Y$, Li L, Chen M, Wang Y, Xu G, et al. [Leukotriene receptor antagonist as addon therapy to intranasal corticosteroids in the treatment of allergic rhinitis: a systematic review]. Lin Chung Er Bi Yan Hou Tou Jing Wai Ke Za Zhi. 2015;29(3):207-11.

32. Wise SK, Lin SY, Toskala E, Orlandi RR, Akdis CA, Alt JA, et al. International Consensus Statement on Allergy and Rhinology: Allergic Rhinitis. Int Forum Allergy Rhinol. 2018;8(2):108-352.

33. Bousquet J, Schunemann HJ, Hellings PW Arnavielhe S, Bachert C, Bedbrook A, et al. MACVIA clinical decision algorithm in adolescents and adults with allergic rhinitis. J Allergy Clin Immunol. 2016;138(2):367-74 e2.

34. Andhale S, Goel HC, Nayak S. Comparison of Effect of Levocetirizine or Montelukast Alone and in Combination on Symptoms of Allergic Rhinitis. Indian J Chest Dis Allied Sci. 2016;58(2):103-5.

35. Seresirikachorn K, Chitsuthipakorn W,
Kanjanawasee D, Khattiyawittayakun L, Snidvongs K. Leukotriene Receptor Antagonist Addition to H1-Antihistamine Is Effective for Treating Allergic Rhinitis: A Systematic Review and Meta-analysis. Am J Rhinol Allergy. 2019;33(5):591-600

36. Stjarne P, Strand V, Theman K, Ehnhage A Control of allergic rhinitis with MP-AzeFlu: a noninterventional study of a Swedish cohort. Rhinology. 2019;57(4):279-86.

37. Seresirikachorn K, Chitsuthipakorn W Kanjanawasee D, Khattiyawittayakun L, Snidvongs $\mathrm{K}$. Effects of $\mathrm{H} 1$ antihistamine addition to intranasal corticosteroid for allergic rhinitis: a systematic review and meta-analysis. Int Forum Allergy Rhinol. 2018;8(10):1083-92

38. Carr W, Bernstein J, Lieberman P, Meltzer E, Bachert C, Price D, et al. A novel intranasal therapy of azelastine with fluticasone for the treatment of allergic rhinitis. J Allergy Clin Immunol. 2012;129(5):1282-9.e10.

39. Scadding G, Bousquet J, Bachert C, Fokkens WJ, Hellings PW, Prokopakis E, et al. Rhinology future trends: 2017 EUFOREA debate on allergic rhinitis. Rhinology. 2019;57(1):49-56

40. Khattiyawittayakun L, Seresirikachorn K, Chitsuthipakorn W, Kanjanawasee D,
Snidvongs K. Effects of double-dose intranasal corticosteroid for allergic rhinitis: a systematic review and meta-analysis. Int Forum Allergy Rhinol. 2019;9(1):72-8.

41. Khattiyawittayakun L, Seresirikachorn K, Chitsuthipakorn W, Kanjanawasee D, Snidvongs K. Effects of decongestant addition to intranasal corticosteroid for chronic rhinitis: a systematic review and meta-analysis. Int Forum Allergy Rhinol. 2018;8(12):1445-53.

Kornkiat Snidvongs

Department of Otolaryngology

Medical School

Chulalongkorn University

1873 Rama 4 Road

Pathumwan, Bangkok 10330

Thailand

Tel: (+66) 2-256-4103

Fax: (+66) 2-252-7787

E-mail: drkornkiat@yahoo.com 